\title{
Asset Pricing Restrictions on Predictability: Frictions Matter*
}

\author{
Frans de Roon ${ }^{\dagger}$ and Marta Szymanowska ${ }^{\ddagger}$
}

November 11, 2011

\begin{abstract}
U.S. stock portfolios sorted on size, momentum, transaction costs, M/B, I/A and ROA ratios, and industry classification show considerable levels and variation of return predictability, inconsistent with asset pricing models. This means that a predictable risk premium is not equal to compensation for systematic risk as implied by asset pricing theory (Kirby 1998). We show that introducing market frictions relaxes these asset pricing moments from a strict equality to a range. Empirically, it is not short sales constraints but transaction costs (below 35 basis points) that help to reconcile the observed predictability with the Fama-French-Carhart fourfactor model and the Chen-Novy-Marx-Zhang three factor model, and partly with the Durable Consumption model. Across the sorts, predictability in industry returns can be reconciled with all models considered with only 25 basis points transaction costs, whereas for momentum and ROA portfolios up to 115 basis points are needed.

JEL classification : G12, G17
\end{abstract}

Keywords: time-series predictability, cross-sectional predictability, asset pricing tests, market frictions

\footnotetext{
${ }^{*}$ We thank Lieven Baele, Marie Dutordoir, Frank de Jong, Anthony Lynch, Buhui Qiu, Geert Rouwenhorst, Laura Starks, Jenke Ter Horst, Allan Timmermann, Chris Veld, Marno Verbeek, Zhenyu Wang, conference participants at the FMA 2007 Annual Meeting and WFA 2009 Annual Meeting, and seminar participants at Rotterdam School of Management, Erasmus University for helpful comments. We are grateful to Ken French, Joel Hasbrouck, Long Chen and Lu Zhang for making data available and to Martijn Boons for research assistance. The usual disclaimer applies.

${ }^{\dagger}$ Department of Finance and CentER for Economic Research, Tilburg Universtity, the Netherlands, email: f.a.deroon@uvt.nl.

${ }^{\ddagger}$ Corresponding author. Department of Finance, Rotterdam School of Management, Erasmus University, P.O. Box 1738, 3000 DR Rotterdam, the Netherlands, email: mszymanowska@rsm.nl, phone: +31104089607, fax: +31104089017 .
} 


\section{Introduction}

It is well recognized that stock returns are to some extent predictable over time, as documented by means of time-series regressions of stock returns on a set of forecasting variables. What remains a puzzle is whether this predictability is an anomaly that could lead markets astray, a rational feature of financial markets that reflects time-varying preferences and expectations, or an anomaly that cannot be exploited by investors because of trading restrictions. Sorting portfolios on size, momentum, transaction costs, market-to-book, investment-to-assets and return-on-assets ratios, and using industry classifications, we indeed find considerable levels and variation of return predictability, inconsistent with asset pricing models. We, then, provide a way to directly assess whether such return predictability is consistent with rational asset pricing when investors face market frictions such as short sales constraints and transaction costs. In particular, we focus on the impact of market frictions on the asset pricing models' ability to capture time-variation in return predictability, and analyze whether cross-sectional differences in return predictability are consistent with what might be expected when predictability is rational.

Rational asset pricing models imply that the joint process of returns and a stochastic discount factor is not predictable in frictionless market. Assuming that investors can trade freely without any costs or constraints, Kirby (1998) shows how to use this relation to infer the values of the coefficients in a predictive regression of asset returns on a set of instruments. His approach indicates that the ability to predict returns must be equal to a risk premium for undertaking systematic risk while following a trading strategy intended to exploit predictability.

We extend this approach by analyzing next to the consistency of the rational asset pricing models with the observed predictability, the cross-sectional differences in return predictability, and taking into account market frictions. We find that the profits from a trading strategy intended to exploit predictability need no longer be equal to a risk premium as implied by rational asset pricing models. The inability to go short or the presence of transaction costs may force investors to deviate from a trading rule that exploits predictability, thus lowering their profits. ${ }^{1}$

Although, especially since the removal of the uptick rule in 2007, investors can easily take short positions in U.S. stock markets, many institutional investors are precluded by their charters from doing so. ${ }^{2}$ At a minimum, our analysis of short sales constraints on predictability in asset returns

\footnotetext{
${ }^{1}$ For unconditional returns, He and Modest (1995) find that the combination of short sale constraints, borrowing constraints and trading costs can reconcile the Consumption-CAPM with U.S. stock market returns. Luttmer (1996), on the other hand, finds low levels of transaction costs (on the order of 50 basis points) to significantly weaken restrictions on the variability of the intertemporal marginal rate of substitution, and finds in his tests little evidence against power utility specifications with low risk-aversion parameters.

${ }^{2}$ Almazan, Brown, Carlson, and Chapman (2004) report that only about $30 \%$ of mutual funds are allowed by their
} 
is relevant to the latter. Transaction costs are known to be important to asset pricing and portfolio holdings, as shown in many papers including He and Modest (1995), Luttmer (1996), Lynch and Balduzzi (2000) and Liu (2004). There is also evidence of substantial cross-sectional and times series variation in transaction costs observed in the markets, transaction costs decreasing over time (Domowitz, Glen, and Madhavan (2001)) and with market cap (Hasbrouck (2009)). It is therefore only natural to analyze the effect of transaction costs on the implications of predictability for asset pricing models.

We analyze different portfolios based on single sorts on size, momentum, transaction costs (TC), market-to-book (M/B), investment-to-assets (I/A) and return-on-assets (ROA) ratios, and industry classification. ${ }^{3}$ Each sort yields ten different, equally weighted portfolios. We find substantial crosssectional variation in return predictability. Across the sorts, predictability (as measured by the $R^{2}$ from predictive regressions) is highest (lowest) in high (low) TC stocks, small (big) stocks, low (high) M/B, I/A and ROA stocks, and loser (winner) stocks. Overall, predictability is strongest in TC-sorted portfolios, lowest in size-sorted portfolios, and comparable for the other five groups of sorted portfolios, with $R^{2}$ 's that are usually between $10 \%$ and $30 \%$, consistent with previous literature.

Our empirical analysis tests two sets of asset pricing models. We use three linear factor models: the CAPM, the Fama-French-Carhart four-factor and the recently introduced three-factor model of Chen, Novy-Marx and Zhang (2010). In addition, we use three consumption-based models: the Consumption-CAPM, the Durable Consumption model of Yogo (2006) and the Ultimate Consumption Risk model of Parker and Julliard (2005).

We show that in frictionless markets these asset pricing models are not consistent with the level of predictability observed in the various sorting portfolios, which confirms Kirby's (1998) findings for size-based portfolios. However our subsequent analysis shows that the predictability is mainly an anomaly that cannot be exploited due to market frictions. Incorporating frictions significantly improves the ability of the asset pricing models to generate levels of predictability consistent with those observed in the market. Empirically, short sales constraints, because they imply unreasonably high levels of alphas, cannot reconcile this predictability, but the presence of transaction costs does, suggesting that unconstrained investors do not profit from predictability by taking short positions.

charters to sell short, while only $3 \%$ do so, and hedge funds, known for shorting, are not able to short an economically significant fraction of shares outstanding (Lamont and Stein (2004)).

${ }^{3}$ The tests' assets are selected based on previous findings that show individual asset returns to be cross-sectionally predictable from the characteristics that underly our sorting and that these characteristics are distinct from one another (e.g., Fama and French (1992); Heston, Rouwenhorst, and Wessels (1999); and Korajczyk and Sadka (2004), among others, deal with the issue of profitability of anomalous strategies). 
Transaction costs as low as 35 basis points monthly suffice to reconcile the observed predictability with the Fama-French-Carhart four-factor and the three-factor model of Chen, Novy-Marx and Zhang (2010). Industry-based portfolios require the lowest level of transaction costs to be reconciled with all asset pricing models (always less than 25 basis points monthly), and momentum and ROA-sorted portfolios the highest level (nearly 115 basis points monthly for the CAPM and consumption-based models). With a three-month holding period, all models can be reconciled with predictability with less than 50 basis points transaction costs. Finally, when sorting on transaction costs, the critical level of transaction costs needed in each decile, is always lower than the actual transaction costs observed for that portfolio. A separate Internet appendix shows our main findings to be robust in an out-of-sample setting.

Our results shed light not only on time-series return predictability, but also on cross-sectional differences in return predictability. We find strong differences across portfolio sorts, predictability being much more difficult to reconcile in momentum and ROA-sorted portfolios than in industry portfolios, and predictability being strongest in high TC-stocks, small stocks, low M/B, low I/A, low ROA, and loser portfolios. Finally, in order for predictability to be consistent with asset pricing models, these most predictable decile portfolios require a substantially higher level of transaction costs than the highest decile portfolios, a result expected if the predictability observed in the market is, indeed, rational.

\section{Consistency of predictability with asset pricing models}

In a standard asset pricing framework, investors maximize their expected utility (over consumption), leading to the first-order conditions

$$
E_{t}\left[m_{t+1} R_{i, t+1}\right]=1
$$

where $m_{t+1}$ is an admissible pricing kernel or stochastic discount factor, $R_{i, t+1}$ is the gross return on asset $i$ and $E_{t}[\cdot]$ indicates the expectation conditioned on the full set of information available at time $t$. This equality states that the joint process $\left(m_{t+1} R_{i, t+1}\right)$, not returns themselves, cannot be predicted using time- $t$ information. We consider below the implications of Equation (1) for predictive regressions.

\subsection{Asset pricing implications for the coefficients in predictive regressions}

Kirby (1998) shows how asset pricing theory restricts measures of predictability from linear regression to certain values in frictionless markets, enabling for testing its consistency. We begin 
by briefly repeating his derivations. ${ }^{4}$

Consider a regression of excess returns $r_{i, t+1}$ on a constant and a set of $K$ instruments $\mathbf{z}_{t}$,

$$
r_{i, t+1}=\beta_{i, u 0}+\beta_{i, u z}^{\prime} \mathbf{z}_{t}+\varepsilon_{i, t+1}
$$

Let $q_{t+1}$ be a normalized pricing kernel that has expectation one, i.e., $q_{t+1}=m_{t+1} / E\left[m_{t+1}\right]$. As $m_{t+1}$ itself, $q_{t+1}$ assigns a price zero to excess returns, $r_{i, t+1}$, and to managed excess returns, $\mathbf{z}_{t} r_{i, t+1}$,

$$
E\left[\left(\begin{array}{c}
q_{t+1} r_{i, t+1} \\
q_{t+1} \mathbf{z}_{t} r_{i, t+1}
\end{array}\right)\right]=\mathbf{0} \Leftrightarrow\left(\begin{array}{c}
E\left[r_{i, t+1}\right]+\operatorname{Cov}\left[q_{t+1}, r_{i, t+1}\right] \\
E\left[\mathbf{z}_{t} r_{i, t+1}\right]+\operatorname{Cov}\left[q_{t+1}, \mathbf{z}_{t} r_{i, t+1}\right]
\end{array}\right)=\mathbf{0} .
$$

Rearranging terms and pre-multiplying by $E\left[x_{t} x_{t}^{\prime}\right]^{-1}$, where $x_{t}=\left(\begin{array}{ll}1 & \mathbf{z}_{t}^{\prime}\end{array}\right)^{\prime}$ we get

$$
\begin{gathered}
\left(\begin{array}{c}
E\left[r_{i, t+1}\right]-\mu_{z}^{\prime} \Sigma_{z z}^{-1} \Sigma_{r z} \\
\Sigma_{z z}^{-1} \Sigma_{r z}
\end{array}\right)-\left(\begin{array}{c}
-\operatorname{Cov}\left[q_{t+1}, r_{i, t+1}\right]+\mu_{z}^{\prime} \Sigma_{z z}^{-1} \operatorname{Cov}\left[q_{t+1}, r_{i, t+1}\left(\mathbf{z}_{t}-\mu_{z}\right)\right] \\
-\Sigma_{z z}^{-1} \operatorname{Cov}\left[q_{t+1}, r_{i, t+1}\left(\mathbf{z}_{t}-\mu_{z}\right)\right]
\end{array}\right)=\mathbf{0},(4 \mathrm{a}) \\
\Leftrightarrow \quad\left(\begin{array}{c}
\beta_{i, u 0} \\
\beta_{i, u z}
\end{array}\right)-\left(\begin{array}{c}
\beta_{i, r 0} \\
\beta_{i, r z}
\end{array}\right)=\mathbf{0} .
\end{gathered}
$$

Here $\mu_{z}=E\left[\mathbf{z}_{t}\right], \Sigma_{z z}=\operatorname{Var}\left[\mathbf{z}_{t}\right]$, and $\Sigma_{r z}=\operatorname{Cov}\left[r_{i, t+1}, \mathbf{z}_{t}\right]$. Equation (4) defines the unrestricted and restricted intercepts, $\beta_{i, u 0}$ and $\beta_{i, r 0}$, and slope coefficients, $\beta_{i, u z}$ and $\beta_{i, r z}$. (See Appendix A for details of the derivations.)

If the predictability we observe in the market is consistent with the asset pricing model, then under the assumption of frictionless markets, the coefficients from predictive regressions are restricted to be exactly equal to the values in the second part of Equation (4a). This means that predictability observed in the market must be consistent with the exposure to systematic risk undertaken by an investor following a trading strategy that exploits predictability (i.e., consistent with the covariance between asset returns and the pricing kernel) and constitutes a basis for a risk premium.

Note that we reject the asset pricing model whenever it generates levels of predictability different from the observed predictability, whether too low or too high. These two cases are not symmetric, however, as the trading strategy aimed at exploiting the mispricing of predictability implies taking either short or long positions respectively. When the actual effect of an instrument in the market is stronger than the model suggests, that is, a payoff from a trading strategy that exploits predictability is higher than a premium required by the actual risk exposure of such a strategy, long positions in such strategies can take advantage of this additional premium. In the opposite situation, when

\footnotetext{
${ }^{4}$ Readers interested in details of the derivations should consult Kirby (1998).
} 
the pricing model overstates the effect of an instrument so that the compensation received in the market is lower than implied by the asset pricing model, investors would like to short sell.

\subsection{Incorporating frictions in the trading process}

Next, we introduce short sales constraints and transaction costs into our economy.

\subsubsection{Short sales constraints}

He and Modest (1995) show that the presence of short sales constraints affects the first-order conditions of the investors' portfolio problem. For excess returns, we obtain

$$
E\left[\left(\begin{array}{c}
q_{t+1} r_{i, t+1} \\
q_{t+1} r_{i, t+1} \mathbf{z}_{t}
\end{array}\right)\right] \leq 0
$$

where we follow He and Modest in assuming that the vector of instruments takes only non-negative values and has an unconditional mean equal to one, $\mu_{z}=\iota^{5}$. It is important to note that we are using excess returns, which means that the no-short-selling constraint pertains only to risky assets.

Pre-multiplying Equation (5) with $E\left[x_{t} x_{t}^{\prime}\right]^{-1}$ we can write Equation (4) as

$$
\left(\begin{array}{c}
\beta_{i, u 0} \\
\beta_{i, u z}
\end{array}\right)-\left(\begin{array}{c}
\beta_{i, r 0} \\
\beta_{i, r z}
\end{array}\right)=\left(\begin{array}{c}
\left(1+\iota^{\prime} \Sigma_{z z}^{-1} \iota\right) E\left[q_{t+1} r_{i, t+1}\right]-\iota^{\prime} \Sigma_{z z}^{-1} E\left[q_{t+1} \mathbf{z}_{t} r_{i, t+1}\right] \\
-\Sigma_{z z}^{-1} \iota E\left[q_{t+1} r_{i, t+1}\right]+\Sigma_{z z}^{-1} E\left[q_{t+1} \mathbf{z}_{t} r_{i, t+1}\right]
\end{array}\right) .
$$

First, we consider a special case in which unconditional returns are assumed to be priced correctly such that $E\left[q_{t+1} r_{i, t+1}\right]=0$. This is an important case since our main focus lies in the impact of market frictions on the conditional trading strategies that exploit predictability (managed returns). This means that the effect of short sales constraints applies to dynamic strategies only. Using this assumption, the first terms on the right-hand-site in Equation (6) become zero and the non-positive second terms (using also that $\Sigma_{z z}$ is positive and diagonal) then imply:

$$
\begin{aligned}
& \beta_{i, u 0}-\beta_{i, r 0} \geq 0 \\
& \beta_{i, u z}-\beta_{i, r z} \leq 0 .
\end{aligned}
$$

To ensure that $\Sigma_{z z}^{-1}>0$ we orthogonalize the instruments, which results in a diagonal variancecovariance matrix $\Sigma_{z z}$. Note that under this assumption the restriction on intercept is redundant since it is equivalent to restricting the sum of the slope coefficients to be non-negative, which is satisfied when restricting only the slope coefficients.

\footnotetext{
${ }^{5}$ Standardizing the mean to be equal to one does not affect the predictive regression coefficients, or $R^{2} s$, but does affect the bounds of the restrictions with short sales constraints and transaction costs. The auxiliary results (available from the authors on request) show that our results are not sensitive to this normalization.
} 
Incorporating short sales constraints into our analysis weakens the restrictions imposed on regression measures of predictability. Investors prohibited from short selling assets may not be able to equate their profits with risk premiums implied by the asset pricing models when the actual effect of some instruments is weaker in the market than the model suggests, that is, $\left(\beta_{i, u z} \leq \beta_{i, r z}\right)$. Thus, an asset pricing model with short sales constraints would be rejected only in the opposite situation, when $\left(\beta_{i, u z} \geq \beta_{i, r z}\right)$, meaning that investors are overcompensated for true risk exposures.

Next, we allow for mispricing also in the unconditional returns, and estimate the minimum value of $E\left[q_{t+1} r_{i, t+1}\right]$ that satisfies the restrictions in Equation (6). Following Chen and Knez (1996), we interpret $\alpha_{J}=E\left[q_{t+1} r_{i, t+1}\right]$ to be an admissible performance measure. From Equation (3), we see that it is equal to the difference between the expected return on an asset and the expectation given its risk exposure, as implied by the asset pricing model. Hence, we refer to this measure as a generalized Jensen's alpha or $\alpha_{J}$. We can then determine whether short sales constraints can reconcile predictability with rational theory by assessing whether these generalized Jensen's alphas are achievable in the market. This enables us to assess whether the required alphas are reasonable in magnitude and high enough to cover potential transaction costs. Then we can draw a conclusion as to whether predictability is consistent with that particular asset pricing model.

\subsubsection{Transaction costs}

To analyze the effect of transaction costs, we follow Luttmer (1996) and differentiate between the return on a long position, $\tau^{A} r_{i, t+1}$, and the return on a short position, $\tau^{B} r_{i, t+1}$ with $\tau^{A} \leq 1 \leq \tau^{B}$. He and Modest (1995) show that in the presence of transaction costs, the restrictions imposed by a valid pricing kernel $q_{t+1}$ on excess asset returns, change to

$$
\left(\begin{array}{c}
\tau_{A} \\
\tau_{A} \iota
\end{array}\right) \leq E\left[\left(\begin{array}{c}
q_{t+1} r_{i, t+1} \\
q_{t+1} z_{t} r_{i, t+1}
\end{array}\right)\right] \leq\left(\begin{array}{c}
\tau_{B} \\
\tau_{B} \iota
\end{array}\right)
$$

where the second set of inequalities follow after taking unconditional expectations and using $\mu_{z}=\iota$.

Combining it with Equation (6), we obtain the following restrictions

$$
\begin{aligned}
\tau_{A}-\iota^{\prime} \Sigma_{z z}^{-1} \iota \Delta & \leq \beta_{i, u 0}-\beta_{i, r 0} \leq \tau_{B}+\iota^{\prime} \Sigma_{z z}^{-1} \iota \Delta \\
-\Sigma_{z z}^{-1} \iota \Delta & \leq \beta_{i, u z}-\beta_{i, r z} \leq \Sigma_{z z}^{-1} \iota \Delta
\end{aligned}
$$

where $\Delta=\tau_{B}-\tau_{A}$. (See Appendix A for details of the derivations.) Note that, unlike the case of short sales constraints, here the restriction on the intercept is binding since it is not guaranteed by the restrictions on the slopes. 
Equation (9) shows that incorporating transaction costs in the tests for predictability weakens the restrictions derived in frictionless markets. The difference between the restricted and unrestricted coefficients should now be within a range determined by the bid-ask spread parameter and a normalization term that accounts for the variability of the instruments. If the instruments are more variable, managed portfolios require more trading and taking larger positions. Hence, small differences in betas may induce large differences in returns. Given the level of transaction costs, this would imply that the difference between $\beta_{i, u z}$ and $\beta_{i, r z}$ must be smaller, which is, indeed, reflected in the multiplication by $\Sigma_{z z}^{-1}$. For the intercept, the bounds are truncated by $\tau_{A}$ and $\tau_{B}$ since with

no instruments $\beta_{i, u 0}-\beta_{i, r 0}$ is simply $E\left[r_{i, t+1}\right]+\operatorname{Cov}\left[q_{t+1}, r_{i, t+1}\right]$, i.e., the mispricing or Jensen's alpha that should be between $\tau_{A}$ and $\tau_{B}$. With instruments there is additional trading required and the bounds on the intercepts become wider by a similar term as for the slope coefficients. This is normalized by the sum of the elements in $\Sigma_{z z}^{-1}$, as all betas affect the intercept. Finally, with no transaction costs, the restrictions in Equation (9) collapse to the frictionless market case. Otherwise, the higher the bid-ask spread the higher the difference between the predictability in the market and that implied by asset pricing models.

By specifying the restrictions as in Equation (9), we can test the extent to which transaction costs can reconcile the predictability in financial markets with asset pricing models. We do so by deriving for the transaction costs a threshold value within the range of which the estimated coefficients will fall. If the level of such a threshold is close to the values of transaction costs observed in the market, we can conclude that predictability is consistent with that particular pricing model.

\section{Measurement issues}

Our empirical analysis considers three linear factor models and three consumption-based models known to be at least partially successful in previous work. To analyze the level of return predictability observed in asset returns, we compare return predictability observed in the data to values restricted by the asset pricing models using $R^{2}$ s and Wald tests.

\subsection{Asset pricing models}

Pricing kernels implied by linear factor models

In general a pricing kernel linear in factors takes the following form:

$$
m_{t+1}=1-\delta^{\prime} f_{t+1},
$$


where $f_{t+1}$ is the vector of factors, and $\delta$ is a vector of parameters assumed to be constant.

As a starting point, we use the Capital Asset Pricing Model (CAPM) of Sharpe (1964) and Lintner (1965) in which the vector $f_{t+1}$ contains only one factor, namely, the return on the market portfolio in excess of the risk-free rate (MKT). We also use the four-factor model (FFC) based on Fama and French (1993) and Carhart (1997), in which the vector $f_{t+1}$ contains, next to the MKT factor, three additional factor-mimicking portfolios: the small minus big portfolio (SMB), the high minus low portfolio (HML), and the up minus down momentum portfolio (UMD).

In addition to these models, we use the three-factor model recently proposed by Chen, NovyMarx, and Zhang (2010) (CNMZ), which is motivated from investment-based asset pricing. In the CNMZ-model the vector $f_{t+1}$ contains the factor (MKT) and two additional investment-based factor-mimicking portfolios: the investment factor (I/A), which is the difference between the return on low-investment stocks and the returns on high-investment stocks, and the ROA factor (ROA), which is the return on a portfolio of stocks with high returns on assets in excess of the return on a portfolio of stocks with low returns on assets. CNMZ show that this model outperforms the Fama-French model in explaining anomalies in the cross-section of stock returns.

\section{Pricing kernels implied by the consumption-based models}

We start with the standard Consumption-CAPM (CCAPM) as introduced by Breeden (1979) for example. Assuming power utility function with constant relative risk aversion $\gamma$, the pricing kernel takes the following form:

$$
m_{t+1}=\delta\left(\frac{C_{t+1}}{C_{t}}\right)^{-\gamma}
$$

where $\delta$ is the time discount factor and $C_{t}$ is the consumption expenditure at time $t$.

Parker and Julliard (2005) propose to extend the contemporaneous measure with the subsequent time periods to account for possible slow consumption adjustment, which gives a pricing kernel of the form,

$$
m_{t+1}^{S}=R_{t, t+S}^{f}\left(\frac{C_{t+S}}{C_{t}}\right)^{-\gamma_{S}}
$$

where $R_{t, t+S}^{f}$ is the risk free rate from time $t$ to $t+S$, and $S$ represents the number of subsequent periods in which the consumption may adjust. For large $S$, this model is referred to as the Ultimate Consumption Risk model.

The above models assume the utility function to be separable across goods and time. Yogo (2006) shows that allowing the marginal utility to be nonseparable improves the model's ability to simultaneously explain the variation in expected returns across stocks and the variation in the equity premium over time. He considers a Durable Consumption model based on Epstein and Zin 
(1991) preferences and a nonseparable utility function in nondurable and durable consumption. This results in the following pricing kernel:

$$
m_{t+1}=\left[\delta\left(\frac{C_{t+1}}{C_{t}}\right)^{-1 / \sigma}\left(\frac{v\left(D_{t+1} / C_{t+1}\right)}{v\left(D_{t} / C_{t}\right)}\right)^{1 / \rho-1 / \sigma} R_{W, t+1}^{1-1 / \kappa}\right]^{\kappa},
$$

where $v(D / C)=\left[1+\alpha\left[(D / C)^{1-1 / \rho}-1\right]\right]^{1 /(1-1 / \rho)}, D_{t}$ is the stock of durable goods, $\kappa=(1-\gamma) /(1-1 / \sigma)$, $\sigma \geqslant 0$ is the elasticity of intertemporal substitution, $\gamma \geqslant 0$ is the relative risk aversion, $\rho \geqslant 0$ is the elasticity of substitution between the two consumption goods, and $\alpha \in(0,1)$ is the fraction of wealth allocated to durable goods.

\subsection{Difference measures}

We start by presenting the estimation procedure for the pricing kernels implied by linear factor models given in Equation (10). In this case, the moment conditions are,

$$
E\left[h\left(r_{i, t+1}, x_{t} ; \theta_{i}\right)\right]=E\left[\begin{array}{c}
f_{t+1}\left(1-\delta f_{t+1}\right) \\
m_{t+1}-\mu_{m} \\
z_{t}-\mu_{z} \\
\left(r_{i, t+1}-\mathbf{x}_{t} \beta_{i, u}\right) \mathbf{x}_{t} \\
\left(-r_{i, t+1}\left(m_{t+1}-\mu_{m}\right)-\mu_{m} \mathbf{x}_{t} \beta_{i, r}\right) \mathbf{x}_{t}
\end{array}\right]=0,
$$

where $r_{i, t+1}$ is the excess return on asset $i, \mathbf{x}_{t}=\left[1, \mathbf{z}_{t}^{\prime}\right], \mathbf{z}_{t}$ is the $(K \times 1)$ vector of forecasting instruments. Also, $\beta_{i, u}=\left(\begin{array}{ll}\beta_{i, u 0} & \beta_{i, u z}^{\prime}\end{array}\right)^{\prime}$ and $\beta_{i, r}=\left(\begin{array}{ll}\beta_{i, r 0} & \beta_{i, r z}^{\prime}\end{array}\right)^{\prime}$. The first moment condition identifies the parameters of the factor model. The subsequent moment conditions identify the means of the pricing kernel and the instruments. The last but one set of moment conditions identifies all unrestricted coefficients in the predictive regressions. Finally, the last set of moment conditions identifies the coefficients restricted by the asset pricing model.

For the consumption-based models, we estimate the additional parameters jointly on all sorted portfolios, hence we obtain one set of parameter values for each model. ${ }^{6}$ For the CCAPM we obtain the coefficient of risk aversion $\gamma=147$. For the Ultimate Consumption Risk model we estimate $\gamma$ to be 69 and allow consumption to adjust over the subsequent 33 months. For the Durable Consumption model, we obtain the following parameter values, the coefficient of risk aversion, $\gamma=142$, the elasticity of intertemporal substitution, $\sigma=0.020$, the elasticity of substitution between the two consumption goods, $\rho=1.07$, and the fraction of wealth allocated to durable

\footnotetext{
${ }^{6}$ The values of parameters estimated separately on each sort do not vary considerable from the ones estimated jointly and hence would have little influence on our results.
} 
goods, $\alpha=0.716$. Our results (available from the authors on request) are robust to reasonable changes in these parameters. Additionally, we require for this model a proxy for the return on wealth for which we use the value weighted market index (following Yogo (2006) and Epstein and $\operatorname{Zin}(1991))$.

The system of equations in (14) is exactly identified, which means that the parameters $\widehat{\beta}_{i, u}$ are exactly the same as the OLS estimates from a linear regression of excess returns on forecasting variables. GMM estimation implies that we solve for $1 / T \sum h\left(r_{i, t+1}, x_{t} ; \widehat{\theta}_{i}\right)=\mathbf{0}$. Under standard regularity conditions, the parameter $\widehat{\theta}_{i}$ is asymptotically distributed as

$$
\sqrt{T}\left(\widehat{\theta}_{i}-\theta\right) \stackrel{d}{\longrightarrow} N\left(0,\left(D_{i}^{\prime} \Omega_{i}^{-1} D_{i}\right)^{-1}\right)
$$

where $D_{i}=E\left[\frac{\partial h}{\partial \theta_{i}}\left(y_{i, t+1}, \theta_{i}\right)\right]$ and $\Omega_{i}=\sum_{j=-\infty}^{\infty} E\left[\mathbf{h}_{i, t} \mathbf{h}_{i, t-j}^{\prime}\right]$.

\subsubsection{Wald test-statistics}

We use a Wald test to evaluate predictability in asset returns. Let $\beta_{i}=\left(\begin{array}{ll}\beta_{i, u} & \beta_{i, r}\end{array}\right)^{\prime}$ be the vector of unrestricted and restricted regression parameters, that is, the last $2(K+1)$ elements of $\theta_{i}$, and $\Lambda_{i}$ its covariance matrix. This unknown covariance matrix can be replaced with a consistent estimator without affecting the limiting distribution of the test statistic. We calculate it as the $(2(K+1) \times 2(K+1))$ submatrix of the asymptotic covariance matrix of the GMM estimator $\widehat{\theta}$ : $\left(D_{i}^{\prime} \Omega_{i}^{-1} D_{i}\right)^{-1}$, which is consistently estimated using the White covariance estimator

$$
\widehat{\Omega}_{i}=T^{-1} \sum_{t=1}^{T} \mathbf{h}_{i, t} \mathbf{h}_{i, t}^{\prime} .
$$

The Wald test-statistics, in frictionless markets, follow from the following minimization ${ }^{7}$

$$
\begin{aligned}
& W_{i}=\min _{\beta_{i}} T\left(\beta_{i}-\widehat{\beta}_{i}\right)\left[\widehat{\Lambda}_{i}\right]^{-1}\left(\beta_{i}-\widehat{\beta}_{i}\right)^{\prime} \\
& \text { subject to }: \beta_{i, u}=\beta_{i, r} .
\end{aligned}
$$

Under the null hypothesis and standard regularity conditions, $W_{i}$ converges to a $\chi_{K+1}^{2}$ distribution, where $(K+1)$ is the number of forecasting instruments (including constant) and restrictions. To address possible small sample bias, we also obtain p-values using Monte Carlo simulations.

\footnotetext{
${ }^{7}$ This follows from Wolak (1987) who showed that the Wald statistic defined as

$$
W_{i}=T\left(R \widehat{\beta}_{i}\right)\left[R \widehat{\Lambda}_{i} R^{\prime}\right]^{-1}\left(R \widehat{\beta}_{i}\right)^{\prime}
$$
}

where $R=\left[I_{K+1},-I_{K+1}\right]$, and $I_{K+1}$ is the $(K+1) \times(K+1)$ identity matrix, is also the optimal value of the objective function defined in (17a). 
In the presence of short sales constraints the Wald test-statistcs follow from

$$
\begin{array}{cl}
W_{i}=\min _{\beta_{i}} T & \left(\beta_{i}-\widehat{\beta}_{i}\right)\left[\widehat{\Lambda}_{i}\right]^{-1}\left(\beta_{i}-\widehat{\beta}_{i}\right)^{\prime} \\
\text { subject to }: & \beta_{i, u 0} \geq \beta_{i, r 0} . \\
& \beta_{i, u z} \leq \beta_{i, r z}
\end{array}
$$

Under this null hypothesis, the Wald test-statistic converges to a mixture of $\chi^{2}$ distributions (Kodde and Palm (1986)) and we can obtain p-values using Monte Carlo simulations.

When transaction costs are introduced the constraint for the minimization problem changes to

$$
\begin{gathered}
W_{i}=\min _{\beta_{i}} T\left(\beta_{i}-\widehat{\beta}_{i}\right)\left[\widehat{\Lambda}_{i}\right]^{-1}\left(\beta_{i}-\widehat{\beta}_{i}\right)^{\prime} \\
\text { subject to : } \begin{array}{c}
\tau_{A}-\iota^{\prime} \Sigma_{z z}^{-1} \iota \Delta \leq \beta_{i, u 0}-\beta_{i, r 0} \leq \tau_{B}+\iota^{\prime} \Sigma_{z z}^{-1} \iota \Delta \\
-\Sigma_{z z}^{-1} \iota \Delta \leq \beta_{i, u z}-\beta_{i, r z} \leq \Sigma_{z z}^{-1} \iota \Delta
\end{array} .
\end{gathered}
$$

Given that these bounds are dependent, we follow the approach suggested by Wolak (1991), who notes that from an asymptotic point of view for each $i$ at most one of the inequalities is relevant, so we test only this relevant restriction. Under the null hypothesis, the Wald test-statistic in the presence of transaction costs converges to a mixture of $\chi^{2}$ distributions, ${ }^{8}$ and we can obtain p-values using simulations. We do account for the estimation error in $\widehat{\Sigma}_{z z}$ when estimating the above Wald test-statistic.

\subsubsection{Regression $R^{2} s$}

Our second measure of restrictions implied by asset pricing models is the difference between the unrestricted $R_{i, u}^{2}$ and restricted $R_{i, r}^{2}$ :

$$
R_{i, u}^{2}-R_{i, r}^{2}=\frac{\beta_{i, u z}^{\prime} \Sigma_{z z} \beta_{i, u z}}{\sigma_{r_{i}}^{2}}-\frac{\beta_{i, r z}^{\prime} \Sigma_{z z} \beta_{i, r z}}{\sigma_{r_{i}}^{2}} .
$$

We then proceed by calculating the admissible differences in $R_{i, u}^{2}$ and $R_{i, r}^{2}$ for the various market setups in our analysis. In the absence of market frictions, the null-hypothesis is that $\beta_{i, u z}=\beta_{i, r z}$, and the admissible difference between $R_{i, u}^{2}$ and $R_{i, r}^{2}$ is zero.

Let $\widetilde{\beta}_{i, z}=\left(\begin{array}{ll}\widetilde{\beta}_{i, u z} & \widetilde{\beta}_{i, r z}\end{array}\right)^{\prime}$ be the solution to the minimization problem in (18a), which in the case of short sales constraints leads to $\widetilde{\beta}_{i, u z} \leq \widetilde{\beta}_{i, r z}$. Hence, the resulting values of $\widetilde{\beta}_{i, u z}$ and $\widetilde{\beta}_{i, r z}$ lead to an admissible difference $R_{i, u}^{2}-R_{i, r}^{2}$ that is consistent with the asset pricing model when short selling is not allowed.

\footnotetext{
${ }^{8}$ This follows from Driessen, Melenberg, and Nijman (2005), who refer to this procedure as local hypothesis testing, and show it to be a special case of the test proposed by Kodde and Palm (1986). As they also show, a global interpretation would imply that we overestimated the size of transaction costs needed to avoid statistical rejection of the model, or, equivalently, underestimated the influence of transaction costs on model misspecification.
} 
Finally, with transaction costs, the solution to the minimization problem in (19a), defined as $\bar{\beta}_{i, z}=\left(\bar{\beta}_{i, u z} \bar{\beta}_{i, r z}\right)^{\prime}$, must fall within the transaction cost bounds. Again, the resulting values of $\bar{\beta}_{i, u z}$ and $\bar{\beta}_{i, r z}$ lead to an admissible difference $R_{i, u}^{2}-R_{i, r}^{2}$ that is consistent with the asset pricing model with transaction costs.

\section{Data and summary statistics}

\subsection{Data description}

Our empirical analysis uses monthly equally weighted portfolios formed on the basis of NYSE, Amex, and Nasdaq stocks. ${ }^{9}$ We classify the universe of stocks independently into ten size, ten market-to-book ratio (M/B), ten momentum, ten investment-to-assets (I/A), ten return-on-assets (ROA), ten transaction costs (TC), and ten industry portfolios.

We obtain from the Kenneth French data library the data on size, M/B, momentum, and industry equally weighted deciles. Equally weighted I/A and ROA deciles are from Chen, NovyMarx, and Zhang (2010) (CNMZ). The estimates of transaction costs are from Hasbrouck (2009). ${ }^{10}$ We use returns, dividends and prices from the Center for Research in Security Prices (CRSP) and accounting information from the Compustat Annual and Quarterly Industrial Files. The sample period is from February 1965 until December 2009. For the ten ROA deciles and the CNMZ factors described below, the sample runs from January 1972 to June 2009, due to the availability of accounting information.

We employ commonly used forecasting variables selected on the basis of findings from previous studies: a dummy for the January effect (Jan); a credit risk premium (Prem) constructed as the difference in yields between Moody's Baa ranked bonds and Moody's Aaa ranked bonds; a term structure premium (Term) constructed as the difference between the 90- and 30-day Treasury bill rate; a dividend yield on the S\&P 500 index (Div); and the lagged return on the market index (Mkt). Except for the January dummy, all of the forecasting variables are lagged one month.

To construct the pricing kernels implied by the linear factor models we obtain data on the FamaFrench-Carhart factors from the Kenneth French data library. For the consumption-based models we use consumption, durable stock, and population data reported by the Bureau of Economic Analysis (BEA). We measure consumption growth as the percentage change in the seasonally

\footnotetext{
${ }^{9}$ Tests run with the value-weighted portfolios lead us to similar conclusions, although we find smaller $R^{2} s$. The results are available from the authors on request.

${ }^{10}$ We are grateful to Ken French, Long Chen, and Joel Hasbrouck for making these data available. We extend the data of CNMZ to match our sample period for the I/A portfolios and use a shorter period from January 1972 to June 2009 for the ROA portfolios, due to the availability of accounting information. To form transaction costs decile portfolios each month we sort CRSP stocks based on their previous year estimate of transaction costs.
} 
adjusted, aggregate, real per capita consumption expenditures on nondurable goods and services. We construct the evolution of the durable stock by iterating forward the initial real value of the durable stock, by adding the real durable expenditure and subtracting a quarterly depreciation rate of $6 \%$.

For the instruments, we base our empirical analysis on the assumption that the variancecovariance matrix of instruments $\Sigma_{z z}$ is diagonal. To satisfy this assumption, we orthogonalize the forecasting variables by regressing them step-wise on each other and a constant, and using the residual terms for the instruments. We also make sure the instruments have mean one by adding a constant.

\subsection{Predictability in sorted portfolio returns}

Table 1 reports in Panel A the $R^{2}$ 's and Wald test-statistics from the OLS regression defined in Equation (2) using all five instruments. Panel B report analogous statistics using the bias-corrected slopes and standard errors proposed by Amihud and Hurvich (2004).

The results in Panel A show that we are able to explain quite a large fraction of stock return variance. We observe substantial cross-sectional variation in predictability across different sorts, the $R^{2}$ 's from the predictive regressions, in general, varying between $5 \%$ and $30 \%$. Moreover, the cross-sectional differences in return predictability are consistent with cross-sectional differences in market size and transaction costs under the assumption that predictability is rational. The portfolio of the highest transaction costs, smallest stocks, lowest market-to-book ratio portfolio and low momentum portfolio have the highest $R^{2}$ 's in our sample. The portfolio with the biggest stocks and the utility industry are the least predictable. Predictability is gradually monotonically decreasing when moving from the first decile (P1) to the last (P10), save for the TC and I/A sorts. For the transaction costs portfolios, as expected under rationality, predictability increases with transaction costs. For the portfolios sorted on I/A we observe a slight U-shaped pattern. ${ }^{11}$

The portfolio with the smallest stocks is considerably more predictable than other size-deciles. When we leave out the portfolio with highest predictability for all sorts, the $R^{2}$ 's are lowest for the size portfolios, roughly half the $R^{2}$ 's for the other sort portfolios. All of the portfolios exhibit $R^{2}$ 's higher than $5 \%$ save for the highest size deciles and one ROA and industry portfolio. ${ }^{12}$

The Wald test-statistics always reject the null hypothesis that all coefficients are zero when we pool all portfolios within each sorting as well as when we treat each portfolio separately, save

\footnotetext{
${ }^{11}$ We also observe a slight increase in $R^{2}$ for $\mathrm{P} 10$ in case of sorts on M/B and ROA.

${ }^{12}$ Numbers similar to those reported in this table are commonly observed in empirical studies of monthly returns on equally weighted portfolios (e.g., Kirby (1998); Ferson and Korajczyk (1995)).
} 
the portfolio of the largest stocks. Also, the majority of the (unreported) slope coefficients are individually significantly different from zero. The pattern of the Wald test-statistics resembles the pattern of the $R^{2}$ 's, except for momentum, where we find little variation in the level of the Wald test-statistics.

Panel B of Table 1 reports analogous statistics but using the Amihud and Hurvich (2004) biascorrection. Although we observe a decrease in the Wald test-statistics when we incorporate it, the bias correction has little influence on the p-values and $R^{2}$ 's. Hence, our conclusion with respect to predictability in test assets is not altered by this small sample bias and we proceed without bias correction in our GMM framework. Moreover, the similarity in $R^{2}$ 's indicates that the bias is not large, and that the differences in Wald test-statistics above are driven mainly by the upward correction to the standard errors. Incorporating this bias-correction in our further analysis would most likely only strengthen our conclusions.

\section{Empirical results}

To see whether the documented predictability is consistent with an asset pricing model, we start from a frictionless market, in which agents can trade without any costs or constraints. We then relax this assumption by introducing first short sales constraints and then proportional transaction costs.

\subsection{Frictionless markets}

The starting point of our analysis is the restriction given in Equation (4). Table 2 presents the results from our seven sets of portfolio sorts and six asset pricing models. Panel A of Table 2 gives the average admissible and realized differences across the portfolios between the restricted and unrestricted $R^{2} s$ for the various asset pricing models. Without market frictions, the admissible difference between unrestricted and restricted $R^{2} s$ should be zero under the null-hypothesis. The results show that the realized differences vary roughly between $5 \%$ and $15 \%$. The smallest differences are observed for the size-based portfolios, and the highest differences are for the M/B and momentum-based portfolios, for all asset pricing models. Across the models, the CNMZ model gives the smallest values for the difference between unrestricted and restricted $R^{2}$. Nevertheless, all the values in Panel A are clearly far from the admissible zero value, and the differences between asset pricing models are fairly small.

Panel B of Table 2 shows the Wald tests for the differences between the restricted and unrestricted slope coefficients. We can clearly reject the null hypothesis for all models and for all 
portfolio sorts. Consistent with the difference between realized and admissible $R^{2}$ 's in Panel $\mathrm{A}$, the Wald test-statistics are smallest for the CNMZ model. Across the sorts, the Wald test-statistics are now highest for the size-based portfolios and lowest for the momentum-based portfolios. However, the size of the test-statistics is such that the null-hypothesis is rejected in all cases and the differences are not very meaningful.

To illustrate, Panels $\mathrm{C}$ and D show differences between unrestricted and restricted regression coefficients for the top and bottom decile of each sort for one linear factor model (FFC) and one consumption-based model (DCM). ${ }^{13}$ Most of the differences are positive except for the coefficients for the term spread and the intercept. The cross-sectional pattern in the coefficients shows that the differences in coefficients are bigger for more predictable portfolios.

\subsection{Short sales constraints}

Because investors may not be able to short sell undesired assets, we allow for the possibility that the premium on conditional strategies earned in the market is smaller than the risk premium implied by the asset pricing model, first assuming the unconditional returns to be priced correctly. In this case, the asset pricing model with short sales constraints is rejected only when investors are overcompensated for true risk exposure. The setup of Table 3 is analogous to the one presented for the frictionless case in the previous table.

Panel A shows the average admissible difference in unrestricted and restricted $R^{2}$ 's to be fairly small, usually about $0.50 \%$, about $0.25 \%$ for the CNMZ model and about one percentage point for the ultimate consumption risk model. In all cases, the realized differences reported below them are well beyond these admissible ones.

In Panel B, we find that an inability to go short does not improve the consistency of predictability with asset pricing models. We observe a decline in Wald test-statistics relative to the frictionless market case but can still reject the null hypothesis for all models and all portfolio sorts at any reasonable level of significance. Apparently, the short positions in dynamic strategies are not crucial for capturing the predictability observed in our sample.

Panels $\mathrm{C}$ and $\mathrm{D}$ show again the differences in regression coefficients, which, consistent with the restrictions, are either zero or positive for the intercept and negative for slope coefficients. We still observe a similar cross-sectional pattern as in the frictionless market case, that differences between coefficients are bigger for more predictable portfolios.

We then relax the assumption that unconditional returns are priced correctly, and allow for

\footnotetext{
${ }^{13}$ Internet appendix reports those differences for the remaining asset pricing models.
} 
simultaneous mispricing in both unconditional and conditional returns. Given the above results, we now ask how much unconditional mispricing (not accessible due to short sales constraints) we must accommodate to reconcile theory with the observed predictability. The starting point are restrictions as given in Equation (6) in which we interpret $\alpha_{J}=E\left[q_{t+1} r_{i, t+1}\right]$ to be a generalized Jensen's alpha measure. We estimate the threshold values of this generalized alpha, which is a minimum value needed to reconcile the asset pricing models with the predictability observed in the portfolio sorts at the $5 \%$ significance level. Table 4 gives the estimated alphas in basis points per month.

Panel A shows that, in all cases, high alphas are needed, with the highest values for the CAPM and Consumption-models. The FFC four-factor model is the only model that requires (absolute) alphas below one percent per month for all sorts save TC-sort. ${ }^{14}$ Across the sorts, the industry portfolios need the lowest level of alphas to be reconciled with predictability, below one percent for all models except the CAPM. The other sorts, in particular the ones based on momentum, ROA, and TC, require alphas as high as $4 \%$ per month.

Panels $\mathrm{B}$ and $\mathrm{C}$ show the values of the alphas needed to reconcile the most and least predictable portfolios. The results show the predictability of the portfolio of stocks with the highest market capitalization (Big), the highest ROA, the lowest TC, and the least predictable industry (Utilities) to require an alpha of only 10 basis points per month for almost all models. We can thus reconcile predictability in these portfolios for all those asset pricing models once short sales constraints are accounted for, with a relatively small alpha. Across the other sorts, the least predictable portfolio can be reconciled with reasonable levels of alpha (below 30 basis points) for the FFC four-factor model and the CNMZ three-factor model save for the TC-sort. This is also so for the Durable Consumption model, with the exception of the I/A-sort. We cannot reconcile any portfolio predictability with asset pricing theory for the most predictable portfolio, as these portfolios require, across all sorts except industries, and asset pricing models, (negative) alphas between $0.50 \%$ and $5.5 \%$ per month.

The estimated alphas suggest that for predictability to be consistent with the asset pricing models in case investors face short sales constraints, unconditional risk premiums must be substantially smaller than implied by the models. Given previous studies of performance evaluation we can see that these minimum values of alphas estimated in Table 4 are above any reasonable level in absolute terms. This means that short sales constraints are not able to reconcile predictability

\footnotetext{
${ }^{14}$ Similar values are obtained by Ferson and Harvey (1999), who find for the Fama-French model alphas of up to $6 \%$ per year for the 25 size and market-to-book ratio portfolios, and up to $11 \%$ per year for the industry portfolios.
} 
save for a number of the highest decile portfolios.

\subsection{Transaction costs}

To determine whether payoffs from predictability are sufficiently high to cover transaction costs, we analyze whether proportional transaction costs can reconcile the predictability observed in the data. Hence, the asset pricing models are only rejected when investors' compensation is outside the bounds determined by the transaction costs given in Equation (9). As transaction costs increase, these bounds increase and the restrictions on the measures of predictability weaken. Table 5 presents the results for transaction costs of 50 basis points.

In terms of differences in $R^{2}$ 's between restricted and unrestricted models in Panel $\mathrm{A}$, we find that the realized difference in $R^{2} s$ still exceeds the admissible differences under the null hypothesis, but they are often of a similar order of magnitude. The admissible $R^{2}$ 's are smallest for the CNMZ model and highest for the UCR model. The differences between the realized and admissible $R^{2}$ 's are often only a few percentage points for all asset pricing models and never exceed $4 \%$, except for a few cases for the UCR model.

The Wald tests in Panel B further highlight the importance of transaction costs. With 50 basis points transaction costs, we are able to reconcile at the $5 \%$ significance level the FFC four-factor and the CNMZ three-factor models for all portfolio sorts, and the Durable Consumption model for four out of seven portfolio sorts. Furthermore, the predictability of the industry portfolios is reconciled for all models. Except for the industry portfolios, the CAPM and UCR models are rejected for all other portfolio sorts. Thus, the Wald test-statistics indicate that the introduction of transaction costs can reconcile observed predictability with at least the FFC and CNMZ models.

Given that the bounds on transaction costs are symmetric around zero we observe in Panels $\mathrm{C}$ and $\mathrm{D}$ the differences between unrestricted and restricted regression coefficients to have both positive and negative signs that are consitent with frictionless markets case. We also see less cross-sectional variation in those differences in comparison to the frictionless market case.

\subsubsection{Critical transaction cost levels}

Given these results, the question arises how much an investor would be required to incur in transaction costs for the documented predictability to be reconciled with the models considered here. Table 6 shows the lowest values of transaction costs for which we cannot reject the null hypothesis at the $5 \%$ significance level. Given that the level of transaction costs is heavily dependent 
on trading frequency, we report the results for two holding periods: one month and three months. ${ }^{15}$ To be on the conservative side, we correct for overlapping observations when quarterly holding periods are used by adjusting the covariance matrix of the estimated parameters by a factor three.

The first thing we notice is that the level of transaction costs needed to reconcile predictability with a particular model varies considerably across the models and portfolio sorts. Panel A gives the values of the transaction costs needed to reconcile the predictability in all portfolios within each sort. For the monthly holding period, the CAPM, CCAPM and Ultimate Consumption Risk models require the highest transaction costs, more than 70 basis points except for the TC and industry portfolios. Consistent with the results in the previous table, the FFC four-factor model and CNMZ three-factor models are reconciled across all portfolio sorts for the one-month holding horizon, with transaction costs below 35 basis points. In addition, the Durable Consumption model can be reconciled with transaction costs below 50 basis points, for all portfolio sorts except size and ROA sorts.

When we move to a three-month holding horizon, the thresholds decrease and we now need 45 basis points to reconcile all models except the Ultimate Consumption Risk model. Also in particular, the performance of the consumption-based models has improved in comparison to a one-month holding period. This is precisely the horizon at which these models were shown to be successful in previous studies. ${ }^{16}$

Across the sorts, the industry portfolios need the lowest levels of transaction costs (up to 25 basis points at the monthly horizon), and the momentum and ROA portfolios the highest levels of transaction costs (up to 113 basis points at the monthly level), to reconcile the observed predictability. At the quarterly level, the differences between the sorts are very small.

Panels $\mathrm{B}$ and $\mathrm{C}$ show the values of transaction costs needed to reconcile predictability in the most and least predictable portfolios. With a one-month holding period, the least predictable portfolio can be reconciled at a relatively low level of transaction cost - less than 30 , and often less than 10, basis points. For the size and industry portfolios, and often for momentum and ROA sorts, the required level of transaction costs is negligible at about two basis points. With a three-month holding period, we need at most 45 basis points for the least predictable portfolio.

\footnotetext{
${ }^{15}$ The difference in results between the one-month and three-month holding periods is driven not only by the differences in trading frequency, but also by the different levels of predictability observed in quarterly as opposed to monthly data. Unreported results (available from the authors on request) reveal for the three-month holding period a pattern of predictability similar to the one observed for the one-month horizon returns (i.e., in terms of cross-sectional dispersion and the significance levels of the slope coefficients), but we find slightly higher $R^{2} s$.

${ }^{16}$ For a comparison with the performance of the consumption-based asset pricing model across the data frequency (monthly, quarterly, and yearly) see Jagannathan and Wang (2007).
} 
It is the most predictable portfolio which is harder for the asset pricing models to capture. Panel A shows that with a monthly horizon, two models are able to reconcile the observed predictability across all portfolio sorts with transaction costs below 35 basis points, but even those are not consistent with the most predictable portfolios save for industries. Only the FFC four-factor model is consistent with the bottom portfolio at a level of transaction costs of 55 basis points. For the CNMZ three-factor model and Durable Consumption model, 95 basis points are needed. With a quarterly holding period, for almost all models and sorts 85 basis points will do, except for the TC portfolios.

Looking across the results for the one- and three-month holding periods, we see that although both the level of predictability and threshold values of transaction costs change, we still need the lowest transaction costs to reconcile the FFC four-factor model, CNMZ three-factor model and Durable Consumption model with the predictability observed in the data. Moreover, the two factor models are reconciled with as few as 35 basis points when investors rebalance their portfolio monthly; all models are reconciled with at most 50 basis points when they trade quarterly, which is consistent with observed levels of transaction costs in the major financial markets.

\subsubsection{Common variation in transaction costs and predictability}

If transaction costs are indeed able to reconcile observed predictability with rational theory, one would expect our difference measures to vary consistently with the level of transaction costs. The results in Table 1 already showed that we find the strongest differences in return predictability across portfolios sorted on transaction costs, predictability being strongest in the highest transaction costs portfolio, which is consistent with our expectations under the assumption that predictability is rational. Likewise, from the estimated critical level of transaction costs, we find the highest TC-portfolio to require a higher level of transaction costs (65 basis points) to be reconciled with rational theory than the lowest TC-portfolio (25 basis points), and these critical transaction costs are smaller than the actual transaction costs associated with these portfolios $(7.08 \%$ and 50 basis points, respectively). Thus, predictability, inconsistent with rational asset pricing in frictionless markets, is stronger in portfolios of stocks that have high transaction costs but can also be reconciled within the observed levels of transaction costs.

Next to this cross-sectional evidence, Figure 1 shows the estimates of the transaction costs, $R^{2}$ 's from predictive regressions and frictionless market Wald test-statistics for size- and TC-sorted portfolios estimated on a rolling window starting in January $1991 .{ }^{17}$ First, the results confirm a de-

\footnotetext{
${ }^{17}$ To conserve space we only report the results for those two sorts as they are the most relevant when linking
} 
creasing trend in transaction costs found in previous studies (e.g., Domowitz, Glen, and Madhavan (2001), Hasbrouck (2009)). Importantly both the $R^{2}$ 's and all Wald test-statistics from frictionless markets are also decreasing over time. Thus, also in the time series, the variation in transaction costs appears to line up with variation in predictability.

In sum, both the time-series and cross-sectional evidence supports the notion that the inability of asset pricing models to generate the observed levels of predictability in frictionless markets, can be reconciled within the bounds of observed transaction costs.

\section{Conclusions}

Our main focus in this study is on the consistency of predictability with asset pricing theory when investors face market frictions such as short sales constraints and transaction costs. Kirby (1998) shows that in frictionless markets, profits from a trading strategy that exploits predictability equal a risk premium implied by asset pricing models. We show that market frictions mitigate these restrictions so that this equality need not be satisfied.

We find that different portfolios, based on single sorts on size, market-to-book ratio, momentum, investment-to-assets, return-on-assets, transaction costs, and industry classification, show substantial cross-sectional variation in return predictability. Our results show that the premium earned in the market when implementing a strategy that tracks predictability is higher than the premium based on a true risk exposure of such strategy, confirming the findings of Kirby (1998). However, these premiums are not sufficiently high to cover transaction costs of fewer than 35 basis points in many cases.

In particular, with transaction costs of 35 basis points, the Fama-French-Carhart four-factor model and the three-factor model by Chen, Novy-Marx, and Zhang (2010) always generate levels of predictability consistent with the ones observed in sorted portfolios. Industry-based portfolios require the lowest level of transaction costs to be reconciled with asset pricing models, momentum and ROA-sorted portfolios the highest.

Our paper uncovers an interesting area of study that we leave for future research. We find that similarly predictable portfolios (e.g., momentum and M/B stocks) are reconciled with different level of market frictions. Hence, better understanding the cross-sectional nature of these portfolios will enable us to better understand the cross-sectional differences in return predictability and vice versa. predictability to transaction costs. The results for the other sorts are available from the authors on request. 


\section{Appendix A. Details of the derivations}

Here, we derive the restrictions given in Section 2 for the markets without frictions and with transaction costs. We start with Equation (3) and pre-multply by $E\left[x_{t} x_{t}^{\prime}\right]^{-1}$ to get

$$
\begin{aligned}
& 0=E\left[\left(\begin{array}{cc}
1 & z_{t}^{\prime} \\
z_{t} & z_{t} z_{t}^{\prime}
\end{array}\right)\right]^{-1} E\left[\left(\begin{array}{c}
q_{t+1} r_{i, t+1} \\
q_{t+1} z_{t} r_{i, t+1}
\end{array}\right)\right] \\
& =\left(\begin{array}{cc}
1+\mu_{z}^{\prime} \Sigma_{z z}^{-1} \mu_{z} & -\mu_{z}^{\prime} \Sigma_{z z}^{-1} \\
-\Sigma_{z z}^{-1} \mu_{z} & \Sigma_{z z}^{-1}
\end{array}\right)\left(\begin{array}{c}
E\left[r_{i, t+1}\right]+\operatorname{Cov}\left[q_{t+1}, r_{i, t+1}\right] \\
E\left[z_{t} r_{i, t+1}\right]+\operatorname{Cov}\left[q_{t+1}, z_{t} r_{i, t+1}\right]
\end{array}\right) \\
& =\left(\begin{array}{c}
E\left[r_{i, t+1}\right]-\mu_{z}^{\prime} \Sigma_{z z}^{-1} \Sigma_{r z} \\
\Sigma_{z z}^{-1} \Sigma_{r z}
\end{array}\right)-\left(\begin{array}{c}
-\operatorname{Cov}\left[q_{t+1}, r_{i, t+1}\right]+\mu_{z}^{\prime} \Sigma_{z z}^{-1} \operatorname{Cov}\left[q_{t+1}, r_{i, t+1}\left(\mathbf{z}_{t}-\mu_{z}\right)\right] \\
-\Sigma_{z z}^{-1} \operatorname{Cov}\left[q_{t+1}, r_{i, t+1}\left(\mathbf{z}_{t}-\mu_{z}\right)\right]
\end{array}\right)
\end{aligned}
$$

which leads to restrictions in frictionless market given in Equation (4a) above.

When transaction costs are present the restrictions imposed by the asset pricing models are given in Equation (8), which together with Equation (6) gives:

$$
\left(\begin{array}{cc}
1+\iota^{\prime} \Sigma_{z z}^{-1} \iota & -\iota^{\prime} \Sigma_{z z}^{-1} \\
-\Sigma_{z z}^{-1} \iota & \Sigma_{z z}^{-1}
\end{array}\right) E\left[\left(\begin{array}{c}
q_{t+1} r_{i, t+1} \\
q_{t+1} \mathbf{z}_{t} r_{i, t+1}
\end{array}\right)\right]=\left(\begin{array}{c}
\beta_{i, u 0} \\
\beta_{i, u z}
\end{array}\right)-\left(\begin{array}{c}
\beta_{i, r 0} \\
\beta_{i, r z}
\end{array}\right)
$$

Note that $-\Sigma_{z z}^{-1} \iota$ is a column vector with only negative elements, while all elements of $\Sigma_{z z}^{-1}$ are non-negative. For the slope coefficients we get:

$$
\beta_{i, u z}-\beta_{i, r z}=-\Sigma_{z z}^{-1} \iota E\left[q_{t+1} r_{i, t+1}\right]+\Sigma_{z z}^{-1} E\left[q_{t+1} \mathbf{z}_{t} r_{i, t+1}\right]
$$

The minimum value of (A.4) is therefore obtained when $E\left[q_{t+1} r_{t+1}\right]=\tau_{B}$ and $E\left[q_{t+1} \mathbf{z}_{t} r_{i, t+1}\right]=$ $\tau_{A} \iota$, while the maximum is obtained when $E\left[q_{t+1} r_{i, t+1}\right]=\tau_{A}$ and $E\left[q_{t+1} \mathbf{z}_{t} r_{i, t+1}\right]=\tau_{B} \iota$. Thus:

$$
\begin{aligned}
-\Sigma_{z z}^{-1} \iota \tau_{B}+\Sigma_{z z}^{-1} \iota \tau_{A} & \leq \beta_{i, u z}-\beta_{i, r z} \leq-\Sigma_{z z}^{-1} \iota \tau_{A}+\Sigma_{z z}^{-1} \iota \tau_{B} \Leftrightarrow \\
-\Sigma_{z z}^{-1} \iota \Delta & \leq \beta_{i, u z}-\beta_{i, r z} \leq \Sigma_{z z}^{-1} \iota \Delta .
\end{aligned}
$$

For the intercept we get:

$$
\beta_{i, u 0}-\beta_{i, r 0}=\left(1+\iota^{\prime} \Sigma_{z z}^{-1} \iota\right) E\left[q_{t+1} r_{i, t+1}\right]-\iota^{\prime} \Sigma_{z z}^{-1} E\left[q_{t+1} \mathbf{z}_{t} r_{i, t+1}\right]
$$

Here we have that $\left(1+\iota^{\prime} \Sigma_{z z}^{-1} \iota\right)>0$, and $\iota^{\prime} \Sigma_{z z}^{-1}$ is also positive. Thus, the minimum value of ( A.6) is obtained when $E\left[q_{t+1} r_{i, t+1}\right]=\tau_{A}$ and $E\left[q_{t+1} \mathbf{z}_{t} r_{i, t+1}\right]=\tau_{B} \iota$, while the maximum is obtained when $E\left[q_{t+1} r_{i, t+1}\right]=\tau_{B}$ and $E\left[q_{t+1} \mathbf{z}_{t} r_{i, t+1}\right]=\tau_{A} \iota$. Thus:

$$
\begin{aligned}
\left(1+\iota^{\prime} \Sigma_{z z}^{-1} \iota\right) \tau_{A}-\iota^{\prime} \Sigma_{z z}^{-1} \iota \tau_{B} & \leq \beta_{i, u 0}-\beta_{i, r 0} \leq\left(1+\iota^{\prime} \Sigma_{z z}^{-1} \iota\right) \tau_{B}-\iota^{\prime} \Sigma_{z z}^{-1} \iota \tau_{A} \Leftrightarrow \\
\tau_{A}-\iota^{\prime} \Sigma_{z z}^{-1} \iota \Delta & \leq \beta_{i, u 0}-\beta_{i, r 0} \leq \tau_{B}+\iota^{\prime} \Sigma_{z z}^{-1} \iota \Delta,
\end{aligned}
$$

which together with Equation ( A.5) is equal to the restrictions given in Equation (9) above. 


\section{References}

Almazan, A., Brown, K., Carlson, M., Chapman, D., 2004. Why constrain your mutual fund manager?. Journal of Financial Economics 73, 289-321.

Amihud, Y., Hurvich, C. M., 2004. Predictive regressions: A reduced-bias estimation method. Journal of Financial and Quantitative Analysis 39, 813-841.

Breeden, D. T., 1979. An intertemporal asset pricing model with stochastic consumption and investment opportunities. Journal of Financial Economics 7, 265-296.

Carhart, M. M., 1997. On persistence in mutual fund performance. Journal of Finance 52, 57-82.

Chen, L., Novy-Marx, R., Zhang, L., 2010. An alternative three-factor model. Unpublished working paper. Washington University, University of Chicago, Unversity of Michigan.

Chen, Z., Knez, P. J., 1996. Portfolio performance measurement: Theory and applications. Review of Financial Studies 9, 511-555.

Domowitz, I., Glen, J., Madhavan, A., 2001. Liquidity, volatility, and equity trading costs across countries and over time. International Finance 4, 221-255.

Driessen, J., Melenberg, B., Nijman, T., 2005. Testing affine term structure models in case of transaction costs. Journal of Econometrics 126, 201-232.

Epstein, L. G., Zin, S. E., 1991. Substitution, risk aversion and the temporal behavior of consumption and asset returns: An empirical analysis. Journal of Political Economy 99, 263-286.

Fama, E. F., French, K. R., 1992. The cross-section of expected stock returns. Journal of Finance $47,427-465$.

Fama, E. F., French, K. R., 1993. Common risk factors in the returns on stocks and bonds. Journal of Financial Econometrics 33, 3-56.

Ferson, W. E., Harvey, C. R., 1999. Conditioning variables and the cross section of stock returns. Journal of Finance 54, 1325-1360.

Ferson, W. E., Korajczyk, R. A., 1995. Do arbitrage pricing models explain the predictability of stock returns?. Journal of Business 68, 309-349.

Hasbrouck, J., 2009. Trading costs and returns from u.s. equities: Estimating effective costs from daily data. Journal of Finance 64, 1445-1477.

He, H., Modest, D. M., 1995. Market frictions and consumption-based asset pricing. Journal of Political Economy 103, 94-117. 
Heston, S., Rouwenhorst, K., Wessels, R., 1999. The role of beta and size in the cross-section of European stock returns. European Financial Management 5, 9-27.

Jagannathan, R., Wang, Y., 2007. Lazy investors, discretionary consumption, and the cross-section of stock returns. Journal of Finance 62, 1623-1661.

Kirby, C., 1998. The restrictions on predictability implied by rational asset pricing models. The Review of Financial Studies 11, 343-382.

Kodde, D. A., Palm, F. C., 1986. Wald criteria for jointly testing equality and inequality restrictions. Econometrica 54, 1243-1248.

Korajczyk, R. A., Sadka, R., 2004. Are momentum profits robust to trading costs?. Journal of Finance 59, 1039-1082.

Lamont, O., Stein, J. C., 2004. Aggregate short interest and market valuations. American Economic Review Papers and Proceedings 94, 29-32.

Lintner, J., 1965. The valuation of risky assets and the selection of risky investments in stock portfolios and capital budgets. Review of Economics and Statistics 47, 13-37.

Liu, H., 2004. Optimal consumption and investment with transaction costs and multiple risky assets. Journal of Finance 59, 289-338.

Luttmer, E. G., 1996. Asset pricing in economies with frictions. Econometrica 64 (6), 1439-1467.

Lynch, A., Balduzzi, P., 2000. Predictability and transaction costs: The impact on rebalancing rules and behavior. Journal of Finance 55, 2285-2309.

Parker, J. A., Julliard, C., 2005. Consumption risk and the cross-section of expected returns. Journal of Political Economy 113, 185-222.

Sharpe, W., 1964. Capital asset prices: A theory of market equilibrium under conditions of risk. Journal of Finance 19, 425-442.

Wolak, F. A., 1987. An exact test for multiple inequality and equality constraints in the linear regression model. Journal of the American Statistical Association 82 (399), 782-793.

Wolak, F. A., 1991. The local nature of hypothesis testing involving inequality constraints in nonlinear models. Econometrica 59, 981-995.

Yogo, M., 2006. A consumption-based explanation of expected stock returns. Journal of Finance 61, 539-580. 


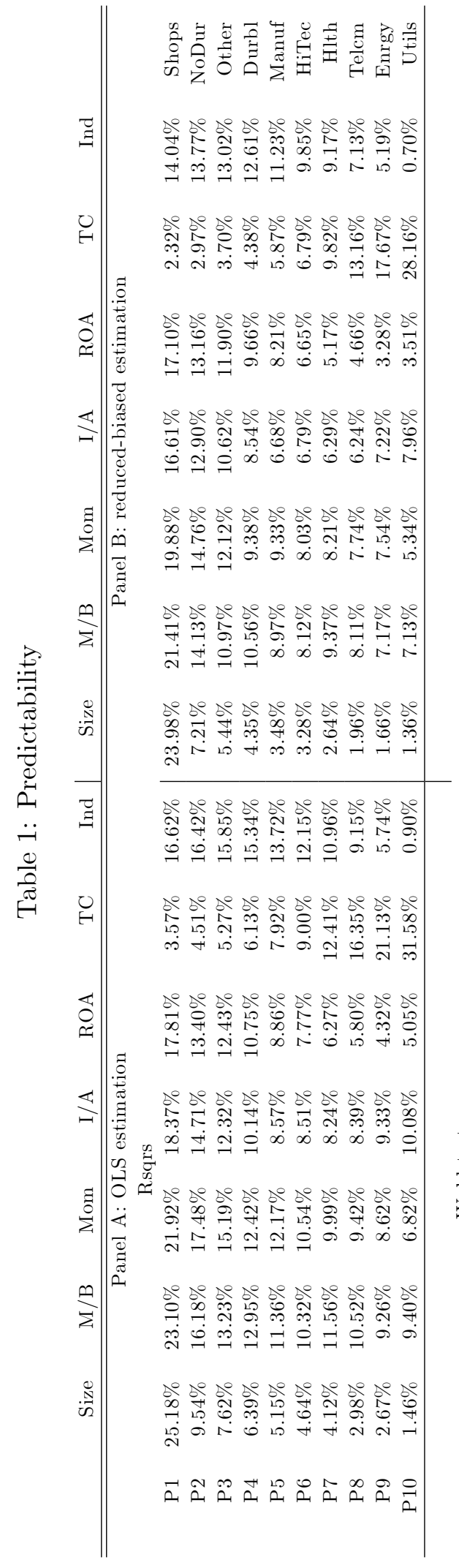

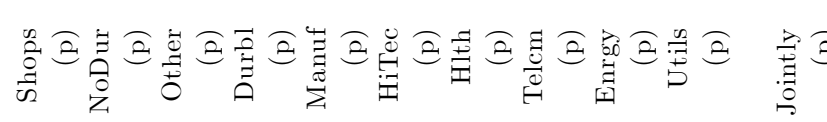

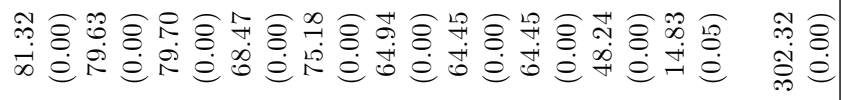

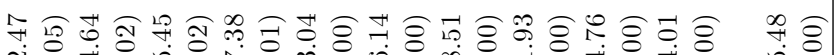

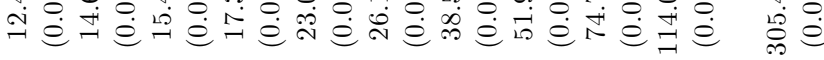

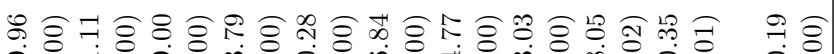

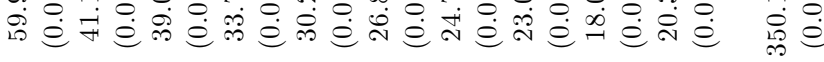
ำ

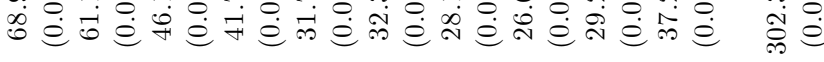
ॠ

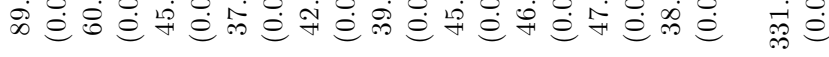

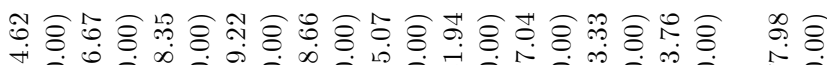

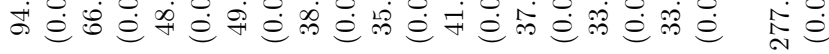

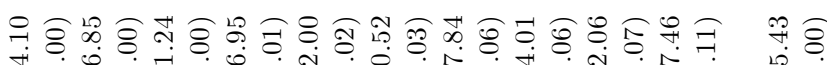

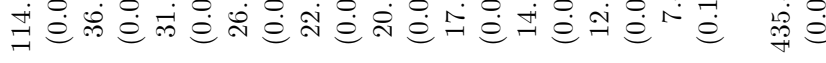

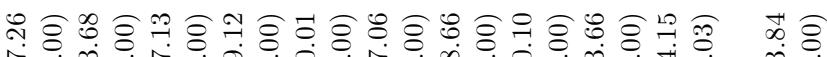

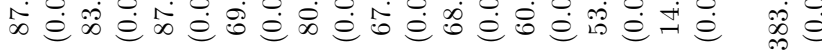

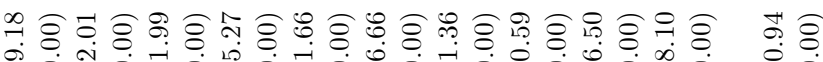

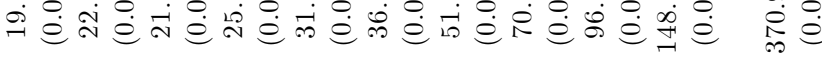

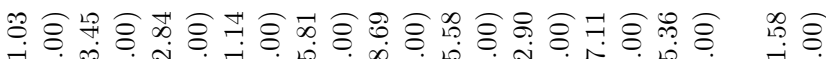

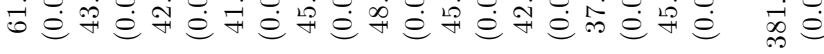

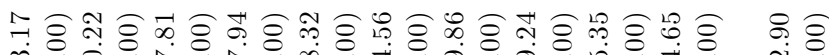

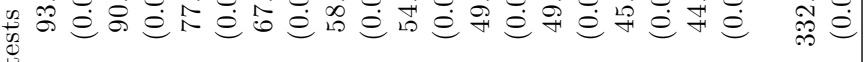

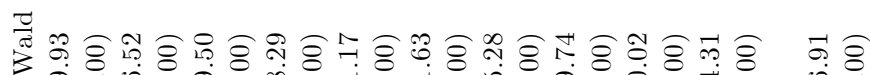

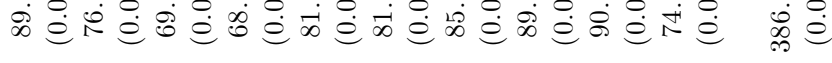

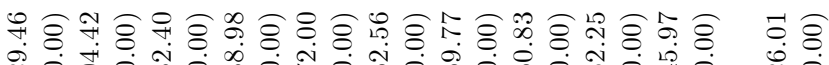

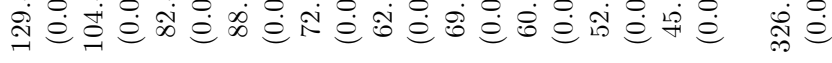

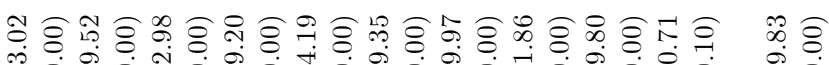

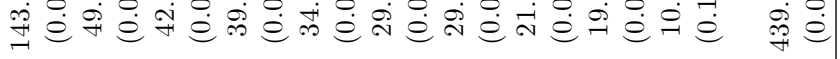

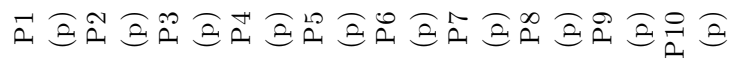
总 
Table 1: Predictability ctd.

Panel A of the table presents the results of fitting the following linear regression model:

$$
r_{i, t+1}=\beta_{i 0}+\beta_{i 1} J_{a n_{t+1}}+\beta_{i 2} \operatorname{Pr} e m_{t}+\beta_{i 3} \text { Term }_{t}+\beta_{i 4} \operatorname{Div}_{t}+\beta_{i 5} M k t_{t}+\epsilon_{t+1} .
$$

We report $R^{2} s$ and the Wald test-statistics from testing the null hypothesis that all slope coefficients are zero within one portfolio and jointly for all portfolios with p-values underneath. P1 is the lowest decile, P10 the highest decile, sorted on size, market-to-book ratio, momentum, I/A, ROA, and transaction costs. The sample period is from February 1965 until December 2009 save for the ROA deciles for which the sample runs from January 1972 to June 2009, due to the availibility of the accounting information.

Panel B presents the reduced-bias estimation of Amihud and Hurvich (2004) of the predictive slopes estimated in Panel A by fitting the following linear regression model:

$r_{i, t+1}=\beta_{i 0}+\beta_{i 1} \operatorname{Jan}_{t+1}+\beta_{i 2}$ Prem $_{t}+\beta_{i 3}$ Term $_{t}+\beta_{i 4}$ Div $_{t}+\beta_{i 5} M k t_{t}+\phi_{2} v_{t, \text { Prem }}^{c}+\phi_{3} v_{t, T e r m}^{c}+\phi_{4} v_{t, \text { Div }}^{c}+\epsilon_{t+1}$.

where $v_{t, j}^{c}$, for each $j=\{$ Prem, Term, Div $\}$, are computed using fitted values from the following firstorder autoregressive AR(1) model:

$$
z_{t, j}=\theta+\rho z_{t-1, j}+v_{t, j}
$$

and using a bias-corrected estimate for $\widehat{\rho}^{c}=\widehat{\rho}+(1+3 \widehat{\rho}) / n+3(1+3 \widehat{\rho}) / n^{2}$. The bias-corrected standard errors take into account estimation error in $\widehat{\rho}^{c}$.

The bias-corrected slope estimates for the predictive instruments (i.e., the $\widehat{\beta}^{c l} s$ ) are used to compute the $R^{2} s$ and the Wald test-statistics analogously to Panel A. 


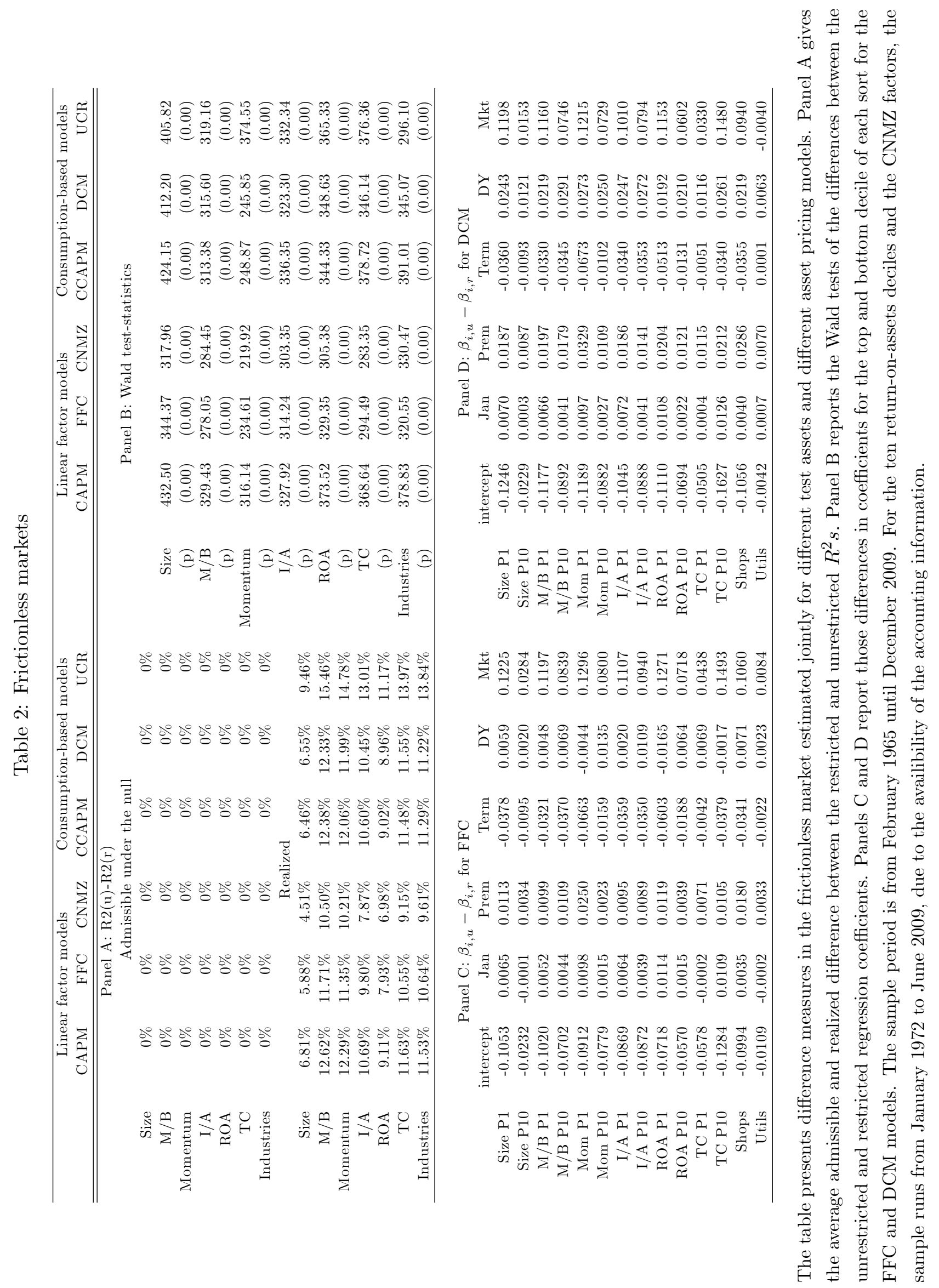




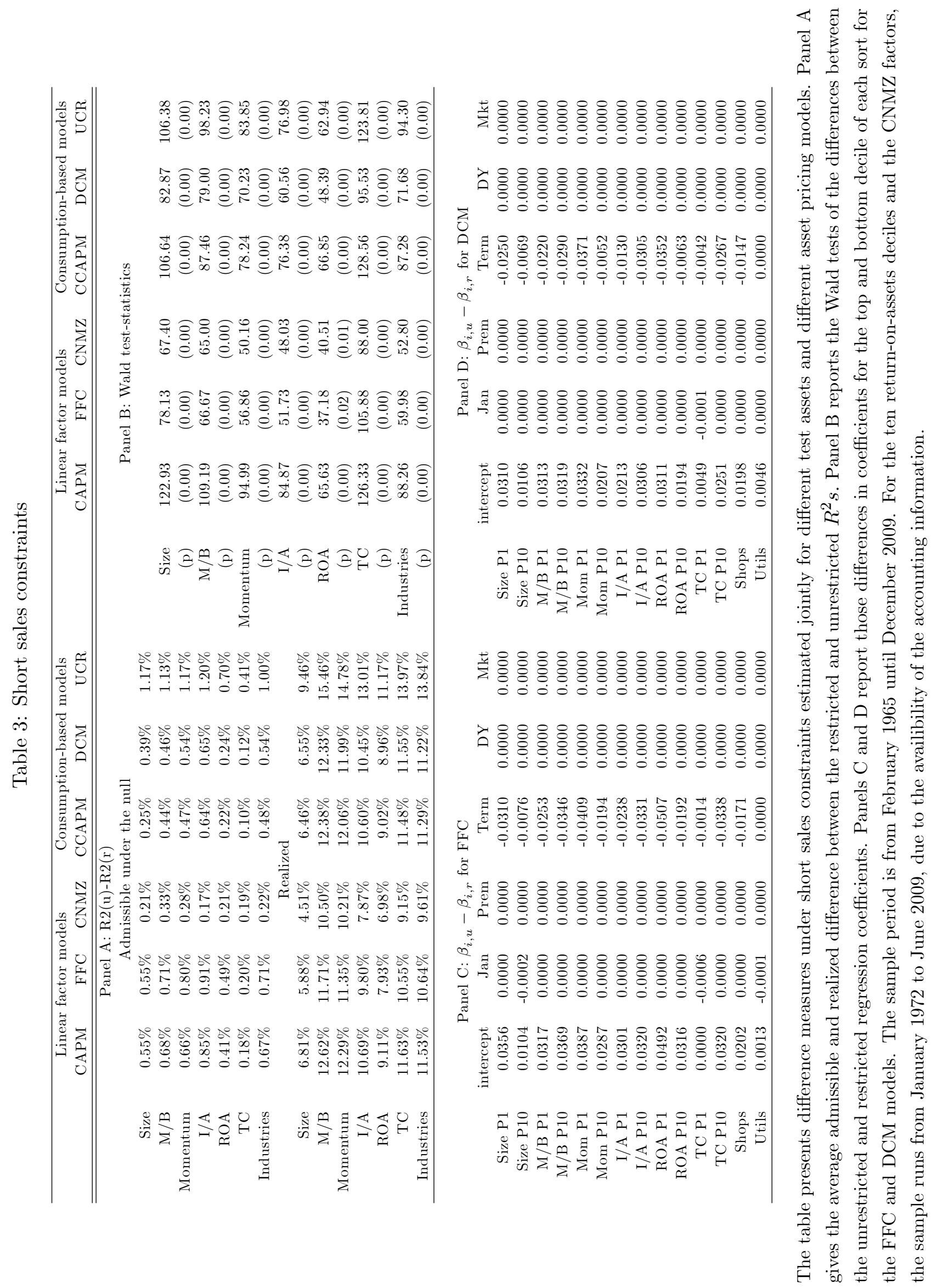


Table 4: The generilized Jensen's alphas

\begin{tabular}{|c|c|c|c|c|c|c|}
\hline & \multicolumn{3}{|c|}{ Linear factor models } & \multicolumn{3}{|c|}{ Consumption-based models } \\
\hline & CAPM & FFC & CNMZ & CCAPM & $\mathrm{DCM}$ & UCR \\
\hline \multicolumn{7}{|c|}{ Panel A: Jointly } \\
\hline Size & -355 & -96 & -154 & -342 & -187 & -355 \\
\hline $\mathrm{M} / \mathrm{B}$ & -285 & -85 & -156 & -287 & -194 & -258 \\
\hline Momentum & -398 & -45 & -96 & -379 & -242 & -398 \\
\hline $\mathrm{I} / \mathrm{A}$ & -290 & -34 & -139 & -287 & -213 & -269 \\
\hline $\mathrm{ROA}$ & -398 & -42 & -183 & -328 & -384 & -398 \\
\hline $\mathrm{TC}$ & -379 & -116 & -203 & -352 & -413 & -355 \\
\hline Industries & -118 & -29 & -32 & -84 & -65 & -96 \\
\hline \multicolumn{7}{|c|}{ Panel B: Most Predictable Portfolio } \\
\hline Small & -420 & -182 & -273 & -420 & -255 & -441 \\
\hline Low M/B & -118 & -161 & -259 & -355 & -269 & -355 \\
\hline Losers & -506 & -83 & -312 & -484 & -341 & -528 \\
\hline $\mathrm{I} / \mathrm{A}$ & -366 & -53 & -226 & -355 & -290 & -275 \\
\hline $\mathrm{ROA}$ & -528 & -96 & -355 & -379 & -342 & -346 \\
\hline $\mathrm{TC}$ & -468 & -299 & -285 & -379 & -364 & -473 \\
\hline Industries & -118 & -52 & -32 & -118 & -53 & -139 \\
\hline \multicolumn{7}{|c|}{ Panel C: Least Predictable Portfolio } \\
\hline Big & -10 & -10 & -10 & -10 & -10 & -10 \\
\hline High M/B & -102 & -22 & -20 & -96 & -27 & -89 \\
\hline Winners & -28 & -20 & -13 & -32 & -21 & -64 \\
\hline $\mathrm{I} / \mathrm{A}$ & -102 & -24 & -27 & -96 & -53 & -37 \\
\hline ROA & -10 & -16 & -10 & -10 & -15 & -15 \\
\hline $\mathrm{TC}$ & -10 & -45 & -53 & -10 & -10 & -10 \\
\hline Industries & -10 & -10 & -10 & -10 & -10 & -10 \\
\hline
\end{tabular}

The table gives the minimum values of the generalized Jensen's alpha in basis points for which we cannot reject the null hypothesis that the difference between the unrestricted and restricted coefficients falls within a short sales constraints bound at the $5 \%$ significance level. The results are based on joint tests for all coefficients across all portfolios (Panel A) and separately for each portfolio (Panel B for the portfolio with the highest predictive $R^{2}$, Panel $\mathrm{C}$ for the portfolio with the lowest predictive $R^{2}$ ). The sample period is from February 1965 until December 2009. For the ten return-on-assets deciles and the CNMZ factors, the sample runs from January 1972 to June 2009, due to the availibility of the accounting information. 


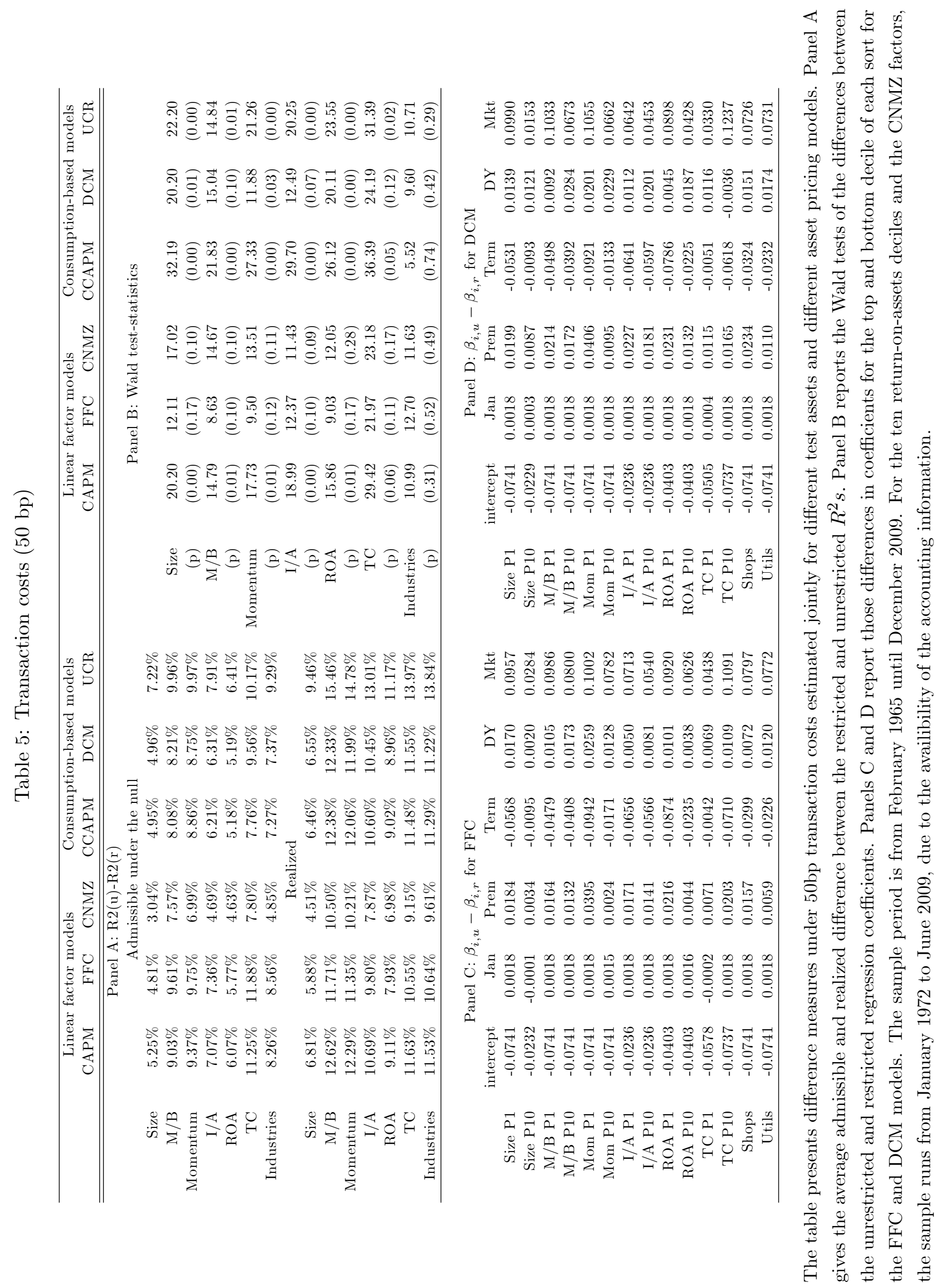




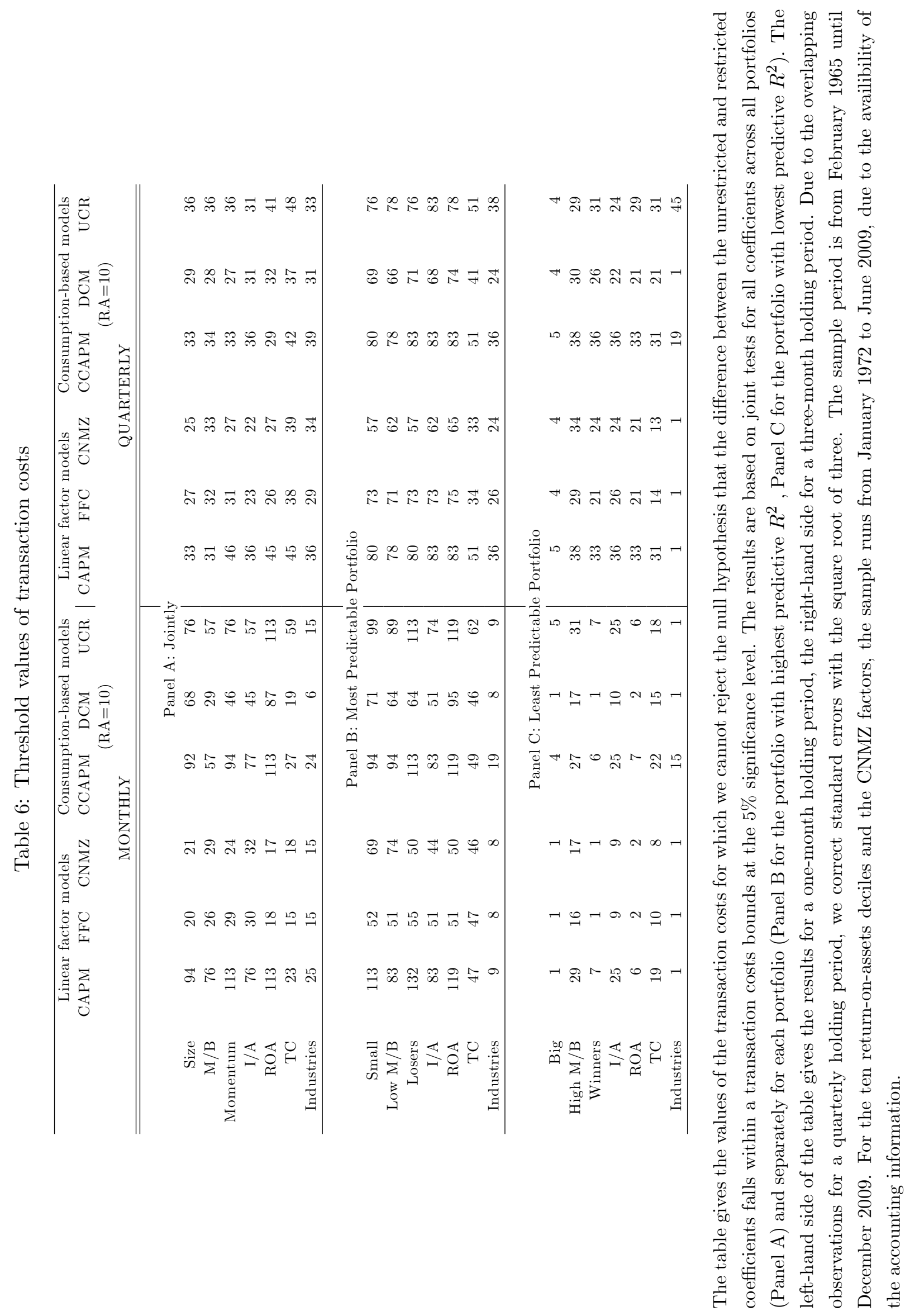



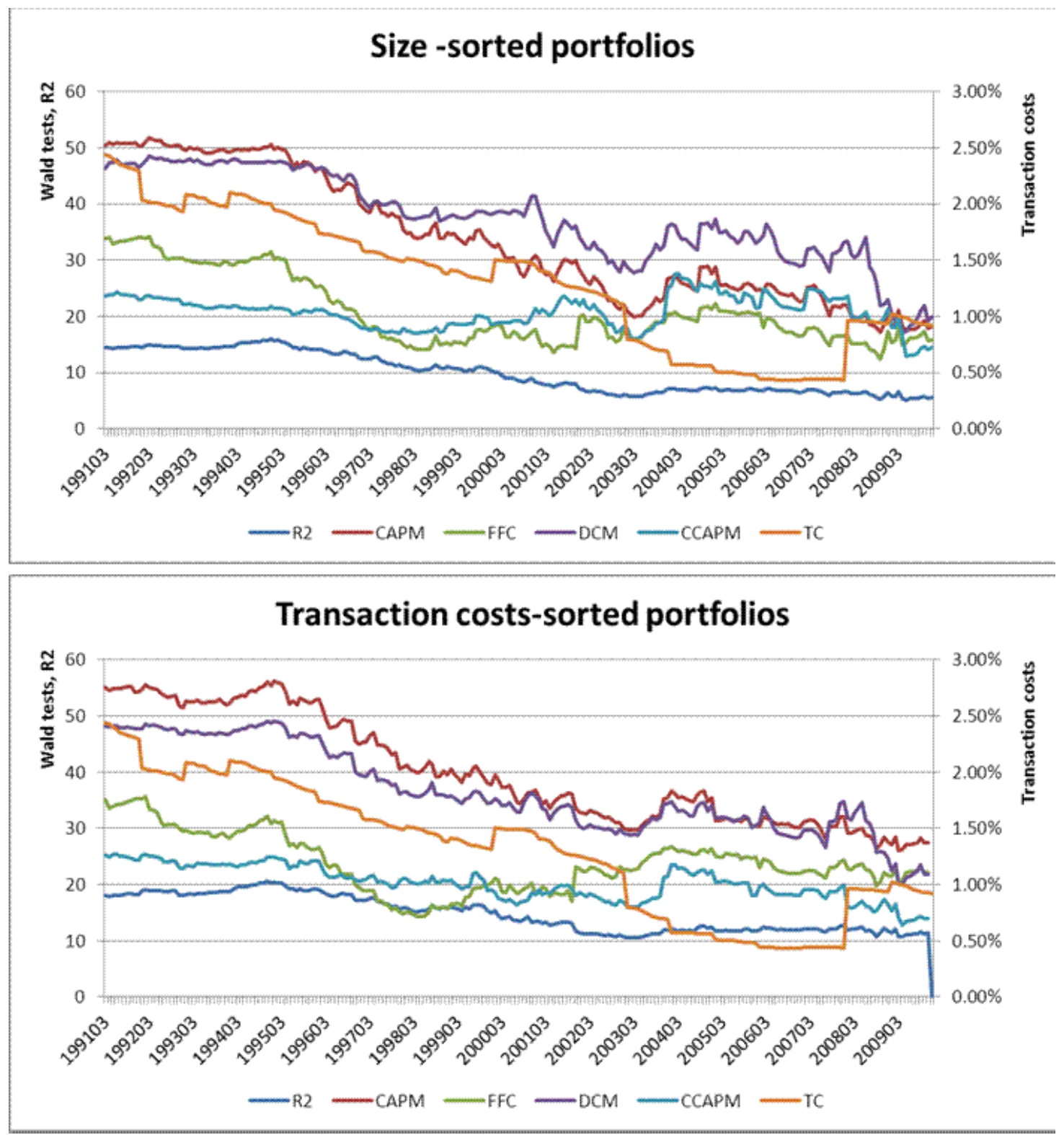

Figure 1: Time-varying predictability measures. 